\title{
Long-Term Survival and Tumor Recurrence in Patients with Superficial Esophageal Cancer after Complete Non-Curative Endoscopic Resection: A Single-Center Case Series
}

\author{
Ji Wan Lee ${ }^{1, *}$, Charles J. Cho ${ }^{1, *}$, Do Hoon Kim ${ }^{1}$, Ji Yong Ahn', Jeong Hoon Lee', Kee Don Choi', Ho June Song', Sook Ryun Park', \\ Hyun Joo Lee ${ }^{3}$, Yong Hee Kim ${ }^{4}$, Gin Hyug Lee', Hwoon-Yong Jung ${ }^{1}$, Sung-Bae Kim², Jong Hoon Kim ${ }^{5}$ and Seung-II Park ${ }^{4}$ \\ Department of ${ }^{1}$ Gastroenterology, ${ }^{2}$ Oncology, ${ }^{3}$ Radiology, ${ }^{4}$ Thoracic and Cardiovascular Surgery, and ${ }^{5}$ Radiation Oncology, \\ University of Ulsan College of Medicine, Asan Medical Center, Seoul, Korea
}

Background/Aims: To report the long-term survival and tumor recurrence outcomes in patients with superficial esophageal cancer (SEC) after complete non-curative endoscopic resection (ER).

Methods: We retrieved ER data for 24 patients with non-curatively resected SEC. Non-curative resection was defined as the presence of submucosal and/or lymphovascular invasion on ER pathology. Relevant clinical and tumor-specific parameters were reviewed.

Results: The mean age of the 24 study patients was $66.3 \pm 8.3$ years. Ten patients were closely followed up without treatment, while 14 received additional treatment. During a mean follow-up of 59.0 \pm 33.2 months, the 3- and 5-year survival rates of all cases were $90.7 \%$ and $77.6 \%$, respectively. The 5 -year overall survival rates were $72.9 \%$ in the close observation group and $82.1 \%$ in the additional treatment group ( $p=0.958$ ). The 5 -year cumulative incidences of all cases of recurrence $(25.0 \%$ vs. $43.3 \%, p=0.388)$, primary EC recurrence $(10.0 \%$ vs. $16.4 \%, p=0.558)$, and metachronous $\mathrm{EC}$ recurrence $(16.7 \%$ vs. $26.7 \%, p=0.667)$ were similar between the two groups.

Conclusions: Patients with non-curatively resected SEC showed good long-term survival outcomes. Given the similar oncologic outcomes, close observation may be an option with appropriate caution taken for patients who are medically unfit to receive additional therapy. Clin Endosc 2018;51:470-477

Key Words: Esophageal carcinoma; Endoscopic resection; Survival; Recurrence

\section{INTRODUCTION}

Endoscopic resection (ER) is a curative therapy for superficial esophageal cancer (SEC) confined to the mucosa without lymphovascular (LV) invasion. On the other hand, additional therapies including esophagectomy, radiotherapy, and/or

Received: January 15, 2018 Revised: April 5, 2018

Accepted: April 25, 2018

Correspondence: Ho June Song

Department of Gastroenterology, University of Ulsan College of Medicine, Asan

Medical Center, 88 Olympic-ro 43-gil, Songpa-gu, Seoul 05505, Korea

Tel: +82-2-3010-3916, Fax: +82-2-485-5782, Email: hjsong@amc.seoul.kr

ORCID: https://orcid.org/0000-0002-3195-8794

*These authors contributed equally to this study.

(c) This is an Open Access article distributed under the terms of the Creative Commons Attribution Non-Commercial License (http://creativecommons.org/ licenses/by-nc/3.0) which permits unrestricted non-commercial use, distribution, and reproduction in any medium, provided the original work is properly cited. chemotherapy are used for non-curatively resected SEC, such as those with submucosal (SM) or LV invasion due to the substantial risk of nodal metastasis. ${ }^{1-3}$ However, the necessity for additional therapy should be considered cautiously because of treatment-related complications and the occurrence of metachronous cancers. Surgical esophagectomy is associated with significant treatment-related mortality of $2.7 \%-13.3 \%{ }^{4.7}$ In addition, subsequent cancer is an important cause of death among patients who undergo curative treatment for EC. ${ }^{8,9}$

In this case series, we report the long-term survival of and tumor recurrence in completely but non-curatively resected SEC patients. The outcomes of patients who were closely observed after non-curative ER were compared to those of patients who received additional therapies. 


\section{MATERIALS AND METHODS}

\section{Patients}

From a consecutively collected database of 209 patients with SEC who underwent ER from June 1999 to June 2014 at our hospital, we identified 24 cases of completely but non-curatively resected SEC with SM or LV invasion. The indications for some ER in these SEC patients included: (1) mucosa-confined tumors $<2 \mathrm{~cm}$ in size; and (2) intraepithelial tumors or high-grade dysplasia of any size. The patients were fully informed about the benefits and risks of ER and surgical esophagectomy. Surgical esophagectomy includes curative nodal dissection and is the standard treatment for SEC. However, ER has some advantages over surgery since it saves organ function and is minimally invasive. Written informed consent was obtained from all patients who underwent ER. In cases of non-curatively resected SEC after ER, surgical esophagectomy was recommended for the harvesting of regional nodes. If patients refused to undergo surgical esophagectomy, we provided additional treatment with radiotherapy and/or chemotherapy. Close observation alone was only permitted when the patient was medically unfit to receive additional therapy or refused any of the treatment options with an understanding of the risk of SEC recurrence. In the 24 patients with non-cu- ratively resected SEC in the current study, 14 underwent additional treatments and 10 were placed on close observation. Fig. 1 presents a clinical flow chart for these patients. The study was approved by the institutional review board of Asan Medical Center (2016-1359).

\section{Endoscopic procedure}

All tumors were evaluated by lugol chromoendoscopy or narrow-band imaging before ER, and SM invasion was assessed by endoscopic ultrasonography. The ER was performed using a single-channel endoscope (GIF-H260; Olympus Optical, Tokyo, Japan). After circumferential marking of the lesion, normal saline containing a mixture of epinephrine $(0.01 \mathrm{mg} /$ $\mathrm{mL}$ ) and indigo carmine was injected into the SM layer and the lifted mucosa was circumferentially incised. Endoscopic SM dissection was performed using an insulated-tip knife 2 (IT knife; Olympus Optical) or IT knife (MTW Endoskopie, Wesel, Germany). Endoscopic mucosal resection was performed using a snare (SD-12U-1 or SD-9U-1; Olympus Optical) after circumferential incision. A UES-30 (Olympus Optical) or VIO 300D (Erbe Elektromedizin, Tübingen, Germany) system was used as the electrosurgical unit. Coagulation of all visible or bleeding vessels on the artificial ulcer was thoroughly performed using hemostatic forceps (FD-410LR; Olympus

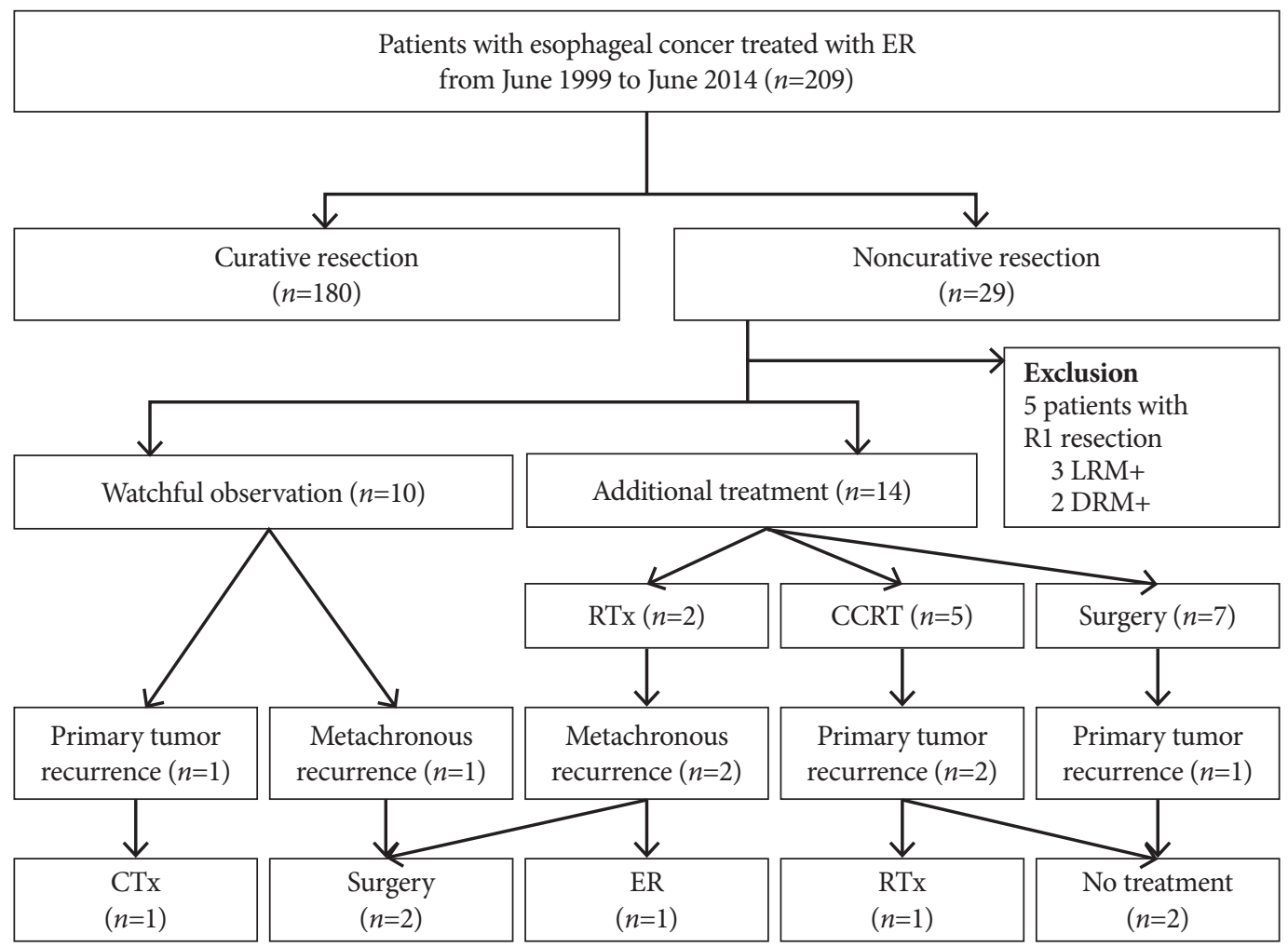

Fig. 1. Follow-up profile of esophageal cancer patients treated with endoscopic resection (ER). LRM, lateral resection margin; DRM, deep resection margin; RTX, radiotherapy; CCRT, concurrent chemoradiotherapy; CTx, chemotherapy. 
Optical).

\section{Pathological definitions}

$\mathrm{R} 0$ en bloc resection was defined as the complete removal of the entire tumor without positive resection margins macroscopically and microscopically. Based on the R0 resection, curative resection for SEC was defined as the resection of tumors confined to the mucosa and the complete absence of SM or LV invasion on microscopic examination. Non-curative resection was defined as at least one instance of SM or LV invasion by the SEC on resection pathology. ${ }^{10-12}$

\section{Additional treatments and follow-up}

Patients who showed non-curative resection on their final ER pathology were recommended to undergo additional treatments such as surgical esophagectomy, radiotherapy, and/ or chemotherapy. Radiotherapy consisted of 45 Gy/25 fractions, and chemotherapy was based on cisplatin and capecitabine. Follow-up endoscopy was performed 3 and 6 months after ER and every 6 months thereafter. All patients underwent chest-abdominal computed tomography with contrast enhancement every 6 months to evaluate regional nodes or distant metastases. Metachronous EC was defined as tumors that developed at the esophagus other than the primary resection site at 1 year after ER.

\section{Statistical analysis}

Variables are presented as a number (percentage) or as a mean \pm standard deviation. Student's $t$-test was used to compare continuous variables, and the chi-square or Fisher's exact test was used to examine categorical variables. Patient survival was calculated with the Kaplan-Meier method and compared with the log-rank test. All p-values were two-sided, and those $<0.05$ were considered significant. All statistical analyses were performed using SPSS version 21 (SPSS Inc., Chicago, IL, USA).

\section{RESULTS}

\section{Clinical and endoscopic features of the study pa- tients}

The mean age of the 24 study patients with non-curatively resected SEC was $66.3 \pm 8.3$ years; 22 (91.7\%) were male (Table $1)$. The tumors were located mostly in the middle third of the esophagus (58.3\%), and the mean tumor size was $16.1 \pm 7.6$ $\mathrm{mm}$. There was one $(4.2 \%)$ case of adenocarcinoma which occurred after Barrett's esophagus. On resection pathology, SM tumor invasion was evident in 21 cases and LV invasion in four cases. Both SM and LV invasions were noted in one patient. Fourteen patients received additional treatments, including surgical esophagectomy $(n=7)$, concurrent chemoradiotherapy $(n=5)$, and radiation therapy $(n=2)$. Four $(16.7 \%)$ patients received ER due to a severe comorbidity: two patients with stroke and two with severe chronic pulmonary disease. Table 1 compares the clinical and tumor-related features of the close observation and additional therapy groups. There were no differences in age, sex, performance status, tumor location and size, and histological tumor invasions between the groups.

\section{Immediate endoscopic outcomes}

Table 2 summarizes the immediate ER outcomes of our study patients. Twenty lesions (83.3\%) were resected by endoscopic SM dissection. The mean endoscopic procedure time was $51.2 \pm 32.8$ minutes. ER-related complications occurred in three patients $(12.5 \%)$, including one of pneumonia and two of severe stricture. The two patients with stricture were treated with endoscopic balloon dilatation. No cases of perforation or bleeding were reported.

\section{Long-term survival and tumor recurrence}

Table 3 and Fig. 2 present the oncologic outcomes of the 24 study patients with non-curatively resected SEC. During a mean follow-up of 59.0 \pm 33.2 months, the 3- and 5-year survival rates of all cases were $90.7 \%$ and $77.6 \%$, respectively. The 5 -year overall survival rate was $72.9 \%$ in the close observation group and $82.1 \%$ in the additional treatment group ( $p=0.958$; Fig. 2A). In addition, the 5-year cumulative incidences of all cases of recurrence ( $25.0 \%$ vs. $43.3 \%, p=0.388$; Fig. $2 \mathrm{~B})$, primary EC recurrence ( $10.0 \%$ vs. $16.4 \%, p=0.558$; Fig. $2 \mathrm{C}$ ), and metachronous EC (16.7\% vs. $26.7 \%, p=0.667$; Fig. $2 \mathrm{D})$ were similar between the close observation and additional treatment groups. Two patients died of a second primary cancer of the lung. Table 4 summarizes the clinical course and treatment outcome of each study patient.

\section{DISCUSSION}

We observed 3- and 5-year survival rates of $90.7 \%$ and $77.6 \%$, respectively, in our current case series of patients with complete non-curatively resected SEC. We also found that the prognosis for our closely observed patients after non-curative ER did not significantly differ from that of the patients who underwent additional treatment. The 5-year overall survival was $72.9 \%$ in the close observation group and $82.1 \%$ in the additional treatment group, which are similar to the reported 5-year survival rates of stage I EC patients: $62 \%-78 \%$ after esophagectomy and $68.6 \%-77 \%$ with chemoradiotherapy. ${ }^{13-18}$ Further, the 5-year cumulative incidences of all cases of recur- 
Table 1. Features of the Analyzed Patients with Non-Curatively Resected Superficial Esophageal Cancer

\begin{tabular}{|c|c|c|c|c|}
\hline & $\begin{array}{l}\text { Total } \\
(n=24)\end{array}$ & $\begin{array}{c}\text { Close observation } \\
(n=10)\end{array}$ & $\begin{array}{l}\text { Additional treatment } \\
\qquad(n=14)\end{array}$ & $p$-value \\
\hline Age, yr & $66.3 \pm 8.3$ & $68.6 \pm 8.0$ & $64.7 \pm 8.4$ & 0.270 \\
\hline Sex, male (\%) & $22(91.7)$ & $10(100)$ & $12(85.7)$ & 0.493 \\
\hline Smoking & $20(83.3)$ & $9(90)$ & $11(78.6)$ & 0.615 \\
\hline Alcohol & $16(66.7)$ & $6(60)$ & $10(71.4)$ & 0.673 \\
\hline Severe comorbidities & $4(16.7)$ & $3(30)$ & $1(7.1)$ & 0.272 \\
\hline ECOG PS & & & & 1.000 \\
\hline 1 & $20(83.3)$ & $8(80)$ & $12(85.7)$ & \\
\hline 2 & $4(16.7)$ & $2(20)$ & $2(14.3)$ & \\
\hline Tumor location & & & & 0.941 \\
\hline Upper & $2(8.3)$ & $1(10)$ & $1(7.1)$ & \\
\hline Middle & $14(58.3)$ & $6(60)$ & $8(57.1)$ & \\
\hline Lower & $8(33.3)$ & $3(30)$ & $5(35.7)$ & \\
\hline Macroscopic type & & & & 0.095 \\
\hline Elevated & $13(54.2)$ & $3(30)$ & $10(71.4)$ & \\
\hline Flat & $11(45.8)$ & $7(70)$ & $4(28.6)$ & \\
\hline Tumor size, mm & $16.1 \pm 7.6$ & $14.7 \pm 7.4$ & $17.2 \pm 7.8$ & 0.439 \\
\hline Tumor histology & & & & 0.417 \\
\hline Squamous cell carcinoma & $23(95.8)$ & $9(90)$ & $14(100)$ & \\
\hline Adenocarcinoma & $1(4.2)$ & $1(10)$ & 0 & \\
\hline \multicolumn{5}{|l|}{ Tumor invasion } \\
\hline Submucosal & $21(87.5)$ & $8(80)$ & $13(92.9)$ & 0.550 \\
\hline Lymphovascular & $4(16.7)$ & $2(20)$ & $2(14.3)$ & 1.000 \\
\hline
\end{tabular}

Data represent the number of patients (\%) or the mean \pm SD.

ECOG PS, Eastern Cooperative Oncology Group performance status; SD, standard deviation.

Table 2. Immediate Endoscopic Outcomes

\begin{tabular}{|c|c|c|c|c|}
\hline & $\begin{array}{c}\text { Total } \\
(n=24)\end{array}$ & $\begin{array}{l}\text { Watchful observation } \\
\qquad(n=10)\end{array}$ & $\begin{array}{l}\text { Additional treatment } \\
\qquad(n=14)\end{array}$ & $p$-value \\
\hline Resection method & & & & 1.000 \\
\hline Mucosal resection & $4(16.7)$ & $2(20)$ & $2(14.3)$ & \\
\hline Submucosal dissection & $20(83.3)$ & $8(80)$ & $12(85.7)$ & \\
\hline Procedure time, minutes & $51.2 \pm 32.8$ & $64.1 \pm 46.0$ & $42.0 \pm 14.9$ & 0.259 \\
\hline Complications & $3(12.5)$ & $2(20)$ & $1(7.1)$ & 0.660 \\
\hline Pneumonia & $1(4.2)$ & 0 & $1(7.1)$ & \\
\hline Stricture & $2(8.3)$ & $2(20)$ & 0 & \\
\hline
\end{tabular}

Data represent the number of patients (\%) or the mean \pm SD.

$\mathrm{SD}$, standard deviation.

rence, primary EC recurrence, and metachronous EC were comparable between groups.

Metastasis to a regional lymph node is a well-known risk factor related to the prognosis of EC. ${ }^{19}$ A number of studies have estimated the risk of lymph node metastasis of SEC, par- ticularly focused on the depth of tumor invasion and presence of $\mathrm{LV}$ invasion. The reported prevalence of nodal involvement is $0 \%-10.3 \%$ when the tumor is limited within the mucosa. ${ }^{2-4}$ Considering the low risk of lymph node metastasis, these cases are indicated for ER and warrant close observation. In a 
Table 3. Long-Term Oncologic Outcomes

\begin{tabular}{lcccc}
\hline & $\begin{array}{c}\text { Total } \\
(\boldsymbol{n}=\mathbf{2 4})\end{array}$ & $\begin{array}{c}\text { Close observation } \\
(\boldsymbol{n}=\mathbf{1 0})\end{array}$ & $\begin{array}{c}\text { Additional treatment } \\
(\boldsymbol{n}=\mathbf{1 4})\end{array}$ & $62.9 \pm 35.4$ \\
\hline Follow-up duration, months & $59.0 \pm 33.2$ & $53.5 \pm 30.8$ & & 0.505 \\
Primary EC recurrence & & & $2(14.3)$ & 0.212 \\
\multicolumn{1}{l}{ Locoregional lymph node } & 2 & 0 & $1(7.1)$ & 0.803 \\
Distant metastasis & 2 & $1(10)$ & $45.3 \pm 24.1$ & 0.500 \\
Recurrence period, months & $36.7 \pm 26.1$ & 11 & $2(14.3)$ & 1.000 \\
Metachronous EC & $3(12.5)$ & $1(10)$ & $3(21.4)$ & 1.000 \\
All-cause death & $5(20.8)$ & $2(20)$ & $2(14.3)$ & 1.000 \\
EC-related death & $3(12.5)$ & $1(10)$ & & \\
\hline
\end{tabular}

Data represent the number of patients (\%) or the mean \pm SD.

EC, esophageal cancer; SD, standard deviation.

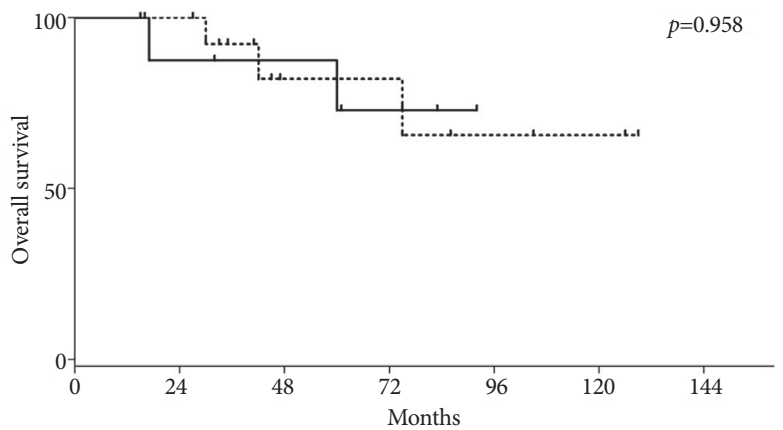

A _ - Watchful observation group ...-Additional treatment group

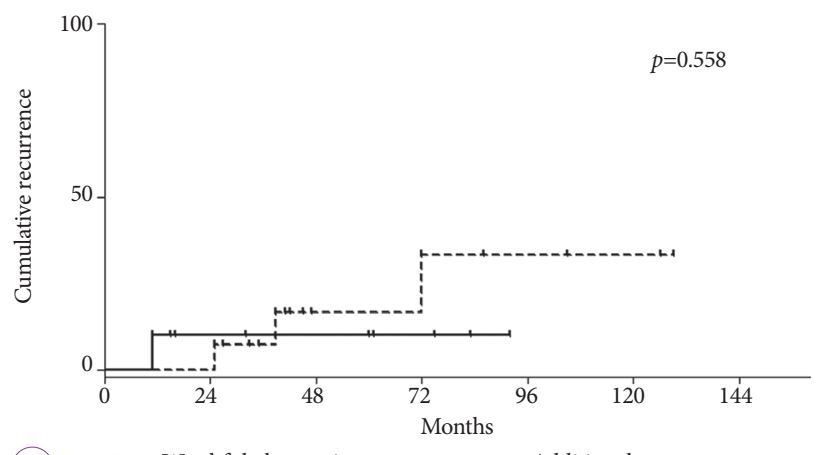

C - Watchful observation group - -1. Additional treatment group

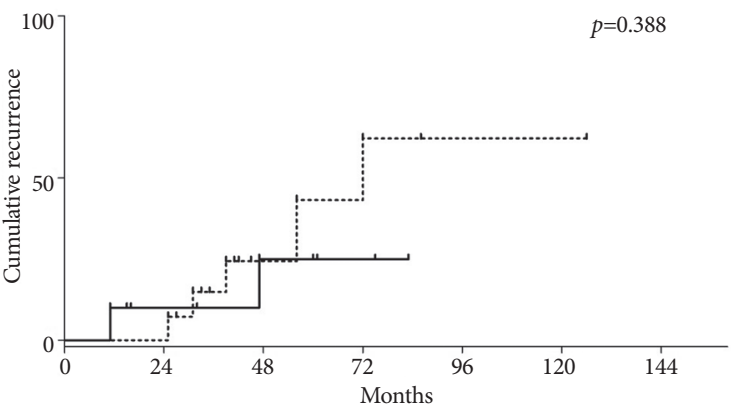

B $\quad \perp$ Watchful observation group $\quad$.... $\quad$ Additional treatment group

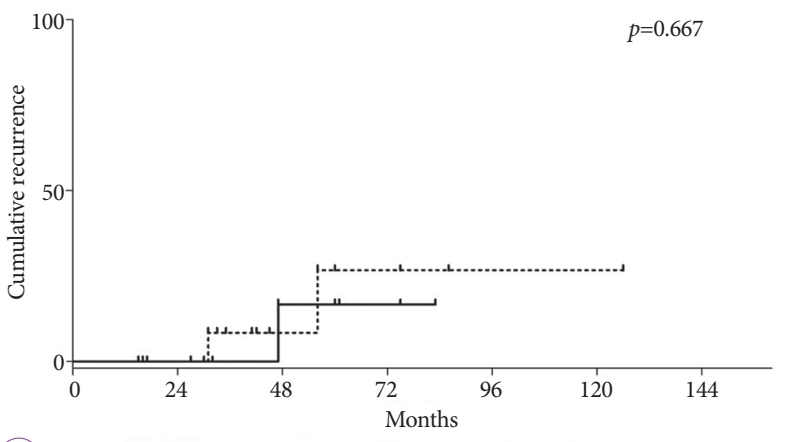

D - Watchful observation group .... Additional treatment group

Fig. 2. The 5-year overall survival (A), 5-year cumulative incidences of all cases of esophageal cancer (EC) recurrence (B), primary EC recurrence (C), and metachronous EC (D) rates in the close observation and additional treatment groups.

retrospective cohort study of 104 SEC patients with mucosal invasion, overall and cause-specific survival rates at 5 years after ER were $79.5 \%$ and $95.0 \%$, respectively, during the median follow-up period of 43 months. ${ }^{20}$ Based on a pathologic analysis of 190 SEC patients who underwent esophagectomy, we previously reported that ER should be performed for mucosal cancers $\leq 3 \mathrm{~cm} .{ }^{11}$ Moreover, if the pathology of the resected specimens reveals invasion of the SM1 layer and a lower mucosal invasion width of $\leq 3.0 \mathrm{~mm}$, the patient can be carefully observed without additional treatment.
Additional treatments for SEC patients with SM or LV invasion after ER are currently accepted as the appropriate course. Although guidelines for selecting the additional therapy are limited, esophagectomy or chemoradiotherapy are typical modalities. ${ }^{2022}$ However, there are few clinical data on the benefits of additional treatment in terms of the long-term prognosis of non-curatively resected SEC patients. A previous study compared the prognosis of 26 SEC patients with tumor invasion to the mucosa or upper third of the submucosa solely treated with ER with that of those treated with esophagec- 


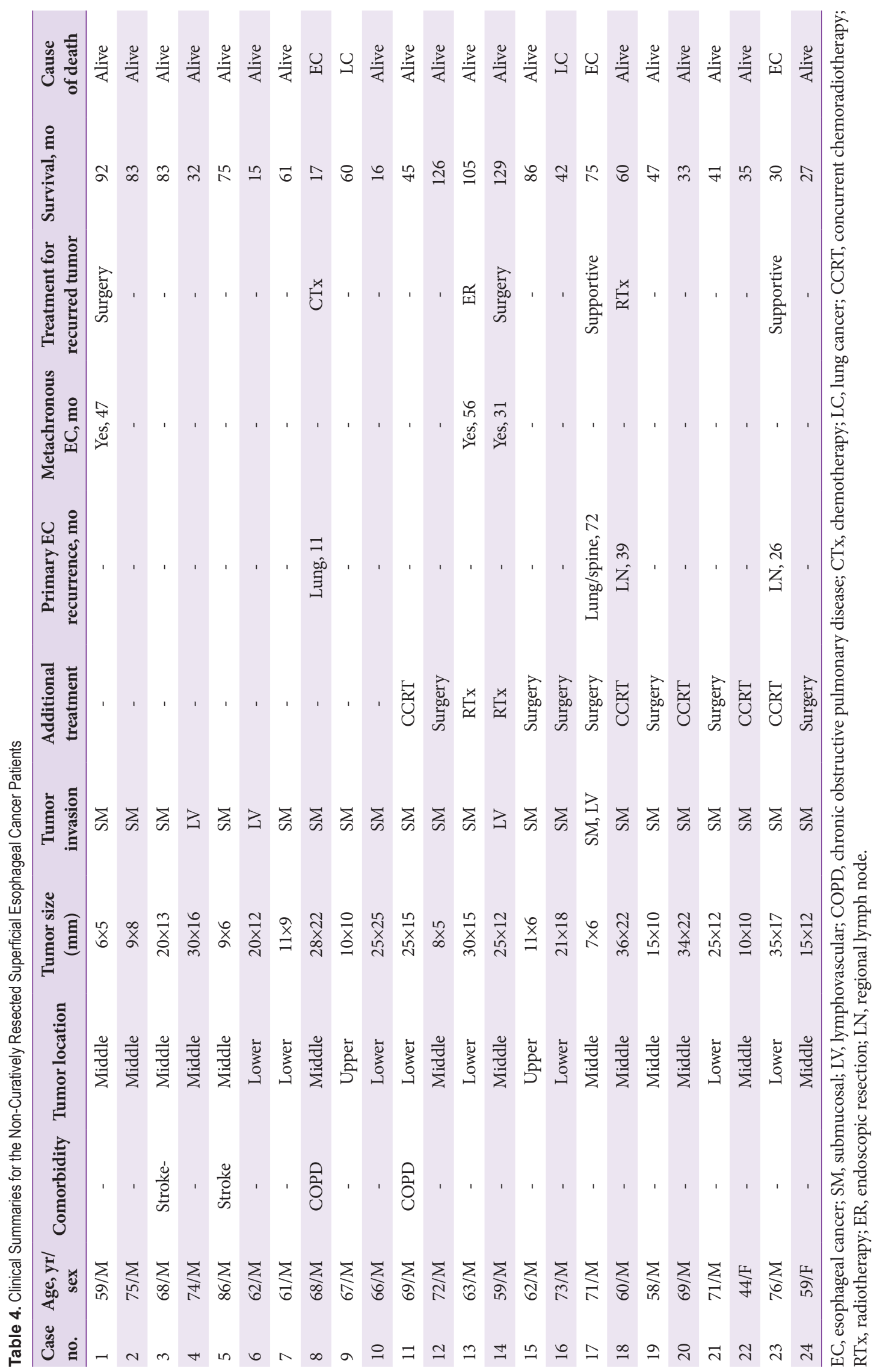


tomy. ${ }^{23}$ They reported no significant difference in the 5-year overall survival rates of patients who underwent esophagectomy and those who underwent ER ( $84.5 \%$ and $77.4 \%, p=0.44)$, nor in their cause-specific survival (93.5\% and 95.0\%, $p=0.73$ ). A recent retrospective analysis of 36 esophageal SEC cases treated with ER reported the clinical course of six non-curatively resected cases. ${ }^{10}$ Five of these patients received additional treatment and one patient was closely observed. During the median follow-up of 31 months, the authors reported no recurrence in the closely observed patients. Among the five patients who underwent additional treatment, one who underwent esophagectomy experienced lymph node recurrence 24 months after the operation and required chemoradiotherapy. In our previous ER data with SEC cohort, a 5-year cumulative survival rate of $79.1 \%$ was noted in patients with SEC invading the submucosa. ${ }^{12}$

The similar prognosis of SEC patients receiving close observation and those receiving additional treatments after non-curative ER may be explained by treatment-related complications and the occurrences of metachronous EC or second primary cancers. The perioperative mortality rates after esophagectomy reportedly range from $2.7 \%$ to $13.3 \%{ }^{4-7}$ In addition, a significant proportion of patients who undergo chemoradiotherapy experience severe toxicity and even death. ${ }^{24}$ Our institutional data indicate post-operative mortality and morbidity rates of $2.1 \%$ and $37.5 \%$, respectively, in patients receiving upfront surgery and chemoradiotherapy-related death and toxicity rates of $3.9 \%$ and $24 \%$, respectively. ${ }^{25}$

Metachronous EC or second primary cancers in other organs are additional concerns following ER for SEC. Indeed, the reported 5-year cumulative incidence of metachronous EC is $16.8 \%-24.5 \%{ }^{26-28}$ In a previous pooled analysis, the 10 year cumulative risk of second primary malignancy after esophagectomy was $34.5 \%$ with an overall relative risk of $2.98 .{ }^{8}$ The risk of head and neck cancer was markedly elevated, followed by the risks of lung cancer and stomach cancer. The 5 -year survival rate after the detection of subsequent malignancy was $45 \%$. We previously reported a $6.6 \%$ incidence of second primary cancers in EC patients at diagnosis and a poor prognosis in these patients with 3- and 5-year survival rates of $25.0 \%$ and $10.6 \%$, respectively. ${ }^{9}$ In the present case series, the 5 -year cumulative incidence of metachronous EC was $16.7 \%$ in the close observation group and $26.7 \%$ in the additional treatment group. The three patients with metachronous EC were treated with subsequent surgery or ER and were all alive during the follow-up period. On the other hand, two of our patients died of second primary cancers of the lung.

The limitation of the current study includes its small number of patients and use of retrospectively collected data in a single institution. However, the results of the current study provide important clues for understanding the pattern, disease course, and prognosis of EC recurrence after non-curative resection.

In summary, our current case series of SEC patients showed good long-term survival outcomes after complete non-curative ER. Given the similar oncologic outcomes compared with additional treatments, close observation may be an option with appropriate caution for patients who are medically unfit to receive additional therapy. Long-term clinical data should be accumulated to facilitate the development of appropriate treatments of SEC after non-curative ER.

Conflicts of Interest

The authors have no financial conflicts of interest.

\section{REFERENCES}

1. Kim DU, Lee JH, Min BH, et al. Risk factors of lymph node metastasis in T1 esophageal squamous cell carcinoma. J Gastroenterol Hepatol 2008;23:619-625.

2. Eguchi T, Nakanishi Y, Shimoda T, et al. Histopathological criteria for additional treatment after endoscopic mucosal resection for esophageal cancer: analysis of 464 surgically resected cases. Mod Pathol 2006;19:475-480.

3. Pimentel-Nunes P, Dinis-Ribeiro M, Ponchon T, et al. Endoscopic submucosal dissection: European Society of Gastrointestinal Endoscopy (ESGE) guideline. Endoscopy 2015;47:829-854.

4. Atkins BZ, Shah AS, Hutcheson KA, et al. Reducing hospital morbidity and mortality following esophagectomy. Ann Thorac Surg 2004;78:11701176; discussion 1170-1176

5. Wright CD, Kucharczuk JC, O'Brien SM, Grab JD, Allen MS. Predictors of major morbidity and mortality after esophagectomy for esophageal cancer: a Society of Thoracic Surgeons General Thoracic Surgery Database risk adjustment model. J Thorac Cardiovasc Surg 2009;137:587-595; discussion 596.

6. Swisher SG, Deford L, Merriman KW, et al. Effect of operative volume on morbidity, mortality, and hospital use after esophagectomy for cancer. J Thorac Cardiovasc Surg 2000;119:1126-1132.

7. Higuchi K, Koizumi W, Tanabe S, et al. Current management of esophageal squamous-cell carcinoma in Japan and other countries. Gastrointest Cancer Res 2009;3:153-161.

8. Matsubara T, Yamada K, Nakagawa A. Risk of second primary malignancy after esophagectomy for squamous cell carcinoma of the thoracic esophagus. J Clin Oncol 2003;21:4336-4341.

9. Lee JS, Ahn JY, Choi KD, et al. Synchronous second primary cancers in patients with squamous esophageal cancer: clinical features and survival outcome. Korean J Intern Med 2016;31:253-259.

10. Park JS, Youn YH, Park JJ, Kim JH, Park H. Clinical outcomes of endoscopic submucosal dissection for superficial esophageal squamous neoplasms. Clin Endosc 2016;49:168-175.

11. Choi JY, Park YS, Jung HY, et al. Feasibility of endoscopic resection in superficial esophageal squamous carcinoma. Gastrointest Endosc 2011;73:881-889, 889.e1-e2.

12. Park HC, Kim DH, Gong EJ, et al. Ten-year experience of esophageal endoscopic submucosal dissection of superficial esophageal neoplasms in a single center. Korean J Intern Med 2016;31:1064-1072.

13. Motoori M, Yano M, Ishihara R, et al. Comparison between radical esophagectomy and definitive chemoradiotherapy in patients with clinical T1bN0M0 esophageal cancer. Ann Surg Oncol 2012;19:2135-2141. 
14. Ura T, Muro K, Shimada Y, et al. Definitive chemoradiotherapy may be standard treatment options in clinical stage I esophageal cancer. J Clin Oncol 2004;22(14 suppl):4017-4017.

15. Shitara K, Muro K. Chemoradiotherapy for treatment of esophageal cancer in Japan: current status and perspectives. Gastrointest Cancer Res 2009;3:66-72.

16. Kato H, Sato A, Fukuda H, et al. A phase II trial of chemoradiotherapy for stage I esophageal squamous cell carcinoma: Japan Clinical Oncology Group Study (JCOG9708). Jpn J Clin Oncol 2009;39:638-643.

17. Pennathur A, Farkas A, Krasinskas AM, et al. Esophagectomy for T1 esophageal cancer: outcomes in 100 patients and implications for endoscopic therapy. Ann Thorac Surg 2009;87:1048-1054; discussion 10541055.

18. Altorki N, Skinner D. Should en bloc esophagectomy be the standard of care for esophageal carcinoma? Ann Surg 2001;234:581-587.

19. Roder JD, Busch R, Stein HJ, Fink U, Siewert JR. Ratio of invaded to removed lymph nodes as a predictor of survival in squamous cell carcinoma of the oesophagus. Br J Surg 1994;81:410-413.

20. Katada C, Muto M, Momma K, et al. Clinical outcome after endoscopic mucosal resection for esophageal squamous cell carcinoma invading the muscularis mucosae--a multicenter retrospective cohort study. Endoscopy 2007;39:779-783.

21. Mochizuki Y, Saito Y, Tsujikawa T, Fujiyama Y, Andoh A. Combination of endoscopic submucosal dissection and chemoradiation therapy for superficial esophageal squamous cell carcinoma with submucosal invasion. Exp Ther Med 2011;2:1065-1068.
22. Molena D, Schlottmann F, Boys JA, et al. Esophagectomy following endoscopic resection of submucosal esophageal cancer: a highly curative procedure even with nodal metastases. J Gastrointest Surg 2017;21:6267.

23. Shimizu Y, Tsukagoshi H, Fujita M, Hosokawa M, Kato M, Asaka M. Long-term outcome after endoscopic mucosal resection in patients with esophageal squamous cell carcinoma invading the muscularis mucosae or deeper. Gastrointest Endosc 2002;56:387-390.

24. Cooper JS, Guo MD, Herskovic A, et al. Chemoradiotherapy of locally advanced esophageal cancer: long-term follow-up of a prospective randomized trial (RTOG 85-01). Radiation Therapy Oncology Group. JAMA 1999;281:1623-1627.

25. Lee JL, Park SI, Kim SB, et al. A single institutional phase III trial of preoperative chemotherapy with hyperfractionation radiotherapy plus surgery versus surgery alone for resectable esophageal squamous cell carcinoma. Ann Oncol 2004;15:947-954.

26. Yamashina $T$, Ishihara $R$, Nagai $K$, et al. Long-term outcome and metastatic risk after endoscopic resection of superficial esophageal squamous cell carcinoma. Am J Gastroenterol 2013;108:544-551.

27. Tsujii $Y$, Nishida T, Nishiyama O, et al. Clinical outcomes of endoscopic submucosal dissection for superficial esophageal neoplasms: a multicenter retrospective cohort study. Endoscopy 2015;47:775-783.

28. Nagami Y, Ominami M, Shiba M, et al. The five-year survival rate after endoscopic submucosal dissection for superficial esophageal squamous cell neoplasia. Dig Liver Dis 2017;49:427-433. 